\title{
Health Care Maintenance of Saudi Elderly Women in Outpatient Clinics
}

\author{
Muneerah albugami ${ }^{1}$, Yasmin Al Twaijri ${ }^{2}$, Hussam Janaid ${ }^{3}$, Abdulwahab Heggi ${ }^{3}$, \\ Abdelazeim Elamin ${ }^{1}$, Rania Abdelreheem ${ }^{4}$, Siddiquee Mohammed ${ }^{1}$, Walae Alahmadi ${ }^{1}$, \\ Noura Alturaif ${ }^{1}$ \\ ${ }^{1}$ Medicine Department, King Faisal Specialist Hospital and Research Center, Riyadh, KSA \\ ${ }^{2}$ Research Centre, Department of Biostatistics, Epidemiology and Scientific Computing, King Faisal Specialist Hospital and Research Center, \\ Riyadh, KSA \\ ${ }^{3}$ Family medicine and polyclinics Department, King Faisal Specialist Hospital and Research Center, Riyadh, KSA \\ ${ }^{4}$ Medicine Department, Faculty of Medicine, Alexandria University, Alexandria, Egypt
}

\section{Email address:}

yasmin@kfshrc.edu.sa (Y. A. Twaijri), hjnaid@kfshrc.edu.sa (H. Janaid), AHEGGI@kfshrc.edu.sa (A. Heggi), abdelazeim@hotmail.com (A. Elamin), ranianaguib2000@yahoo.com (R. Abdelreheem), msiddiquee@kfshrc.edu.sa (S. Mohammed), dr.w.alahmadi@hotmail.com (W. Alahmadi), NALTURAIF92@kfshrc.edu.sa (N. Alturaif )

\section{To cite this article:}

Muneerah albugami, Yasmin Al Twaijri, Hussam Janaid, Abdulwahab Heggi, Abdelazeim Elamin, Rania Abdelreheem, Siddiquee Mohammed, Walae Alahmadi, Noura Alturaif. Health Care Maintenance of Saudi Elderly Women in Outpatient Clinics. American Journal of Internal Medicine. Vol. 3, No. 5, 2015, pp. 197-203. doi: 10.11648/j.ajim.20150305.11

\begin{abstract}
Lifestyle modifications, screenings, early identification, and appropriate intervention may prevent many chronic conditions that cause morbidity and mortality in elderly women. The objective of our study is to describe the current clinical practice of preventive health services (screening, counselling and immunization) among elderly women. This is a retrospective chart review study from January 2009 to December 2011.
\end{abstract}

Keywords: Elderly, Functional Status, Life Expectancy, Health Maintenance, Preventive Care

\section{Introduction}

Elderly has been defined as a chronological age of 65 years old or older. Early elderly is from $65-74$ years old where late elderly is over 75 years old. Saudi Arabia is facing the challenge of an ageing population. According to the last Saudi census in 2011 the life expectancy at birth is 74.Across the industrialized world, women still live 5 to 10 years longer than men. Studies suggest that elderly in the US, and women in particular, receive screening tests that are inappropriate for their age or health status, and do not receive other screening tests and preventive interventions (e.g. immunizations) that are recommended for health maintenance ${ }^{(1.2)}$. A comprehensive review of preventive health measures for elderly women at academic primary care practice in Boston found that many older women were not screened for depression, osteoporosis, or counseled about exercise, falls, or incontinence. Many in poor health were screened for cancer ${ }^{(3)}$.A survey of Saudi elderly between January 1994 and December 1995 found that the poor health perception was twice high among elderly females as in males, and is more with advanced age above 75 years. It is clear that elderly women are more dependent and need more care and attention ${ }^{(4)}$.

Life expectancy is predicted by health status than by age alone. Guidelines recommend considering an older woman's general health when making screening decisions. Screening should be targeted to healthy older women and should be avoided in women with limited life expectancies ${ }^{(5)}$.The goal of preventive medicine in elderly should be not only reduction of premature morbidity and mortality but preservation of function and quality of life ${ }^{(6)}$.Health Maintenance is a systematic program planned to maintain maximum function, improve quality of life and to prevent common conditions of aging. Lifestyle modifications, screenings, early identification, and appropriate intervention may prevent many chronic conditions that cause morbidity and mortality in elderly women.

The objective of our study is to describe the current clinical practice of preventive health services (screening, counselling and immunization) among elderly women in medical 
outpatient clinics at King Faisal Specialist hospital \& Research Centre (KFSH\&RC) which is a governmental hospital. Surgical clinics usually don't provide preventive health services. Exclusion criteria include history of dementia, history of cancer and patients visiting for follow up at medical Protocol clinics or family medicine clinics.

\section{Methods}

It is a retrospective chart review study of elderly women aged $65 \mathrm{y}$ and older who received regular care at KFSH\&RC in internal medicine and medical polyclinics from January 2009 to December 2011. They have at least three visits to clinic in the prior 24 months.

Mammography screening defined as women having had a mammogram in the past 2 years and did not have a history of breast cancer. Colon cancer screening is defined as women having undergone a colonoscopy in the past 10 years, or had a flexible sigmoidoscopy in the past 5 years, or fecal occult blood in the past year and did not have a history of colon cancer. Cervical cancer screening is defined as women having had a PAP smear test in the past 3 years and still had a uterus. Osteoporosis screening defined as women having a bone densitometry screening during the study period. Women were considered to have been screened for depression if patient was referred to psychiatric clinic or patient is taking antidepressant medications or documented in the patient's chart that psychiatric referral was discussed with patient during the study period. Vaccination is defined as women having received a pneumococcal vaccination in the last 5 years or influenza vaccination during the study period. Women were considered to have received counselling about exercise if it is documented in the patient's chart that there was recommendation for exercise. Women were considered to have received diet counselling if it was documented in the patient's chart that there was recommendation about diet control or referrals to a nutritionist.

\section{Statistical Analysis}

For this retrospective study, all the statistical analysis of data was done by using the software package SAS version 9.4 (SAS Institute Inc., Cary, NC, USA) and SPSS version 20 (SPSS, IBM, USA). Descriptive statistics for the continuous variables are reported as mean \pm standard deviation and categorical variables are summarized as frequencies and percentages. Continuous variables are compared by Student's paired t-test while categorical variables are compared by Chisquare test. The level of statistical significance is set at $p<$ 0.05 .

\section{Results}

From January 2009 to December 2011 the total number of patients seen in the internal medicine clinic is 64368 and in the medical polyclinic is 15066 . The number of women aged $65 \mathrm{y}$ and older is 341 . The patient was counted only once regardless of the number of visits to the clinics. We excluded 20 women because either they were not followed up or their follow up visits were less than 3 during the study period. Final number of patients is 321 .

The basic characteristics are shown in table 1. Majority of patients were seen in medical polyclinics $74.62 \%$. Mean age is 73.6. Total number of age $65-79$ is 278 and age 80 and above is 43 . The health maintenance services of elderly women are shown in table 2.

Table 1. Basic characteristics of elderly women.

\begin{tabular}{|c|c|c|c|c|c|}
\hline Total no. $=321$ & Number & Percent (\%) & Median & $\begin{array}{l}(\text { age } 65-79) \\
\text { Total no. }=278\end{array}$ & $\begin{array}{l}\text { (age } 80 \text { and above) } \\
\text { Total no. }=43\end{array}$ \\
\hline Age & & & 72.6 & & \\
\hline Total BMI $(\mathrm{BMI}=$ body mass index $)$ & 321 & & 33.9 & MeanBMI $=34.2$ & MeanBMI=31.1 \\
\hline Clinic visits internal medicine & 61 & $17.74 \%$ & & & \\
\hline medical polyclinics & 244 & $74.62 \%$ & & & \\
\hline both & 16 & $7.64 \%$ & & & \\
\hline Comorbid conditions: Hypertension & 293 & 86.18 & & $250(86.8 \%)$ & $43(13.2 \%)$ \\
\hline Diabetes mellitus & 235 & 69.32 & & $200(87.3 \%)$ & $35(12.7 \%)$ \\
\hline Dyslipidemia & 204 & 60.36 & & $174(87 \%)$ & $30(13 \%)$ \\
\hline ischemic heart disease & 84 & 24.71 & & $74(89.2 \%)$ & $10(10.8 \%)$ \\
\hline Heart failure & 29 & 8.58 & & $25(86.2 \%)$ & $4(13.8 \%)$ \\
\hline Osteoarthritis & 161 & 47.35 & & $135(85.4 \%)$ & $26(14.6 \%)$ \\
\hline Osteoporosis & 91 & 26.84 & & $73(83.9 \%)$ & $18(16.1 \%)$ \\
\hline Previous cerebral vascular accident (CVA) & 22 & 6.51 & & $15(68.2 \%)$ & $7(31.8 \%)$ \\
\hline Br. Asthma & 55 & 16.18 & & $46(88.5 \%)$ & $9(11.5 \%)$ \\
\hline COPD & 7 & 2.06 & & $7(100 \%)$ & 0 \\
\hline $\mathrm{HCV}$ & 28 & 8.26 & & $25(89.3 \%)$ & $3(10.7 \%)$ \\
\hline HBV & 7 & 2.06 & & $7(100 \%)$ & 0 \\
\hline Liver cirrhosis & 10 & 2.94 & & $8(80 \%)$ & $2(20 \%)$ \\
\hline Renal disease & 57 & 16.91 & & $46(82.1 \%)$ & $11(17.9 \%)$ \\
\hline chronic kidney disease in patients had Renal disease & 44 & 78.57 & & $34(79.1 \%)$ & $10(20.9 \%)$ \\
\hline Investigations: Fasting glucose for disease management & 227 & 66.76 & & $192(86.9 \%)$ & $35(13.1 \%)$ \\
\hline Fasting glucose for screening & 94 & 31.47 & & $89(84.8 \%)$ & $5(15.2 \%)$ \\
\hline Lipid profile for disease management & 202 & 60 & & $172(85.6 \%)$ & $30(14.4 \%)$ \\
\hline Lipid profile for screening & 115 & 35.59 & & $104(89.7 \%)$ & $11(10.3 \%)$ \\
\hline
\end{tabular}




\begin{tabular}{|c|c|c|c|c|c|}
\hline Total no. $=321$ & Number & Percent (\%) & Median & $\begin{array}{l}\text { (age } 65-79) \\
\text { Total no. }=278\end{array}$ & $\begin{array}{l}\text { (age } 80 \text { and above) } \\
\text { Total no. }=43\end{array}$ \\
\hline Unknown Lipid profile & 4 & & & & \\
\hline Vitamin D level for disease management & 147 & 48.67 & & $117(84.1 \%)$ & $30(15.9 \%)$ \\
\hline Vitamin D level for screening & 161 & 51.33 & & $151(88.8 \%)$ & $10(11.2 \%)$ \\
\hline Unknown Vitamin D level & 13 & & & & \\
\hline TSH for disease management & 123 & 34.41 & & $101(88.6 \%)$ & $22(11.4 \%)$ \\
\hline TSH for screening & 183 & 56.76 & & $165(87.8 \%)$ & $18(12.2 \%)$ \\
\hline Unknown TSH & 15 & & & & \\
\hline Polypharmacy More than 5 medications & 274 & 83.98 & & $240(87.8 \%)$ & $34(12.2 \%)$ \\
\hline Less than 5 medications & 42 & 13.95 & & $35(84.1 \%)$ & $7(15.9 \%)$ \\
\hline Unknown & 5 & & & & \\
\hline Functional status documentation in patient charts & 146 & 43.32 & & $125(87.4 \%)$ & $21(12.6 \%)$ \\
\hline Full independent & 53 & 36.30 & & $48(90.6 \%)$ & $5(9.4 \%)$ \\
\hline requiring the assistance of another person & 37 & 26.71 & & $34(91.9 \%)$ & $3(8.1 \%)$ \\
\hline Bed bound & 16 & 8.22 & & $9(75 \%)$ & $7(25 \%)$ \\
\hline Using wheelchair & 41 & 28.77 & & $34(82.9 \%)$ & $7(17.1 \%)$ \\
\hline Unknown & 69 & & & & \\
\hline
\end{tabular}

Table 2. The health maintenance services of elderly women.

\begin{tabular}{|c|c|c|c|c|}
\hline Total no. $=321$ & Number & Percent (\%) & $($ age $65-79)$ Total no. $=278$ & (age 80 and above) Total no. $=43$ \\
\hline \multicolumn{5}{|l|}{ Screening } \\
\hline \multicolumn{5}{|l|}{ Mammography } \\
\hline yes & 43 & 12.80 & $38(92.7 \%)$ & $5(7.3 \%)$ \\
\hline no & 270 & 87.2 & $245(86.3 \%)$ & $25(13.7 \%)$ \\
\hline Unknown & 8 & & & \\
\hline \multicolumn{5}{|l|}{ Pap smear: } \\
\hline$-\mathrm{No}$ & 299 & 91.69 & $260(86.4 \%)$ & $39(13.6 \%)$ \\
\hline -Yes & 10 & 8.31 & $7(94 \%)$ & $3(6 \%)$ \\
\hline Unknown & 12 & & & \\
\hline \multicolumn{5}{|l|}{ Colonoscopy } \\
\hline yes & 21 & 9.64 & $17(14 \%)$ & $4(12.5 \%)$ \\
\hline no & 270 & 90.36 & $241(86 \%)$ & $29(87.5 \%)$ \\
\hline Unknown & 30 & & & \\
\hline \multicolumn{5}{|c|}{ Flexible sigmoidoscopy } \\
\hline yes & 16 & 8.41 & $13(14.1 \%)$ & $3(10.7 \%)$ \\
\hline no & 275 & 91.59 & $255(85.9 \%)$ & $20(14.1 \%)$ \\
\hline Unknown & 30 & & & \\
\hline \multicolumn{5}{|l|}{ Faecal occult } \\
\hline yes & 39 & 15.32 & $34(14.6 \%)$ & $5(9.8 \%)$ \\
\hline no & 264 & 84.68 & $234(85.4 \%)$ & $30(90.2 \%)$ \\
\hline Unknown & 18 & & & \\
\hline \multicolumn{5}{|c|}{ Immunization: Influenza: } \\
\hline -No & 198 & 65.18 & $169(84.4 \%)$ & $29(15.6 \%)$ \\
\hline -Yes & 100 & 29.76 & $91(91 \%)$ & $9(9 \%)$ \\
\hline Unknown & 23 & & & \\
\hline \multicolumn{5}{|l|}{ Pneumococcal: } \\
\hline$-\mathrm{No}$ & 272 & 83.04 & $234(86 \%)$ & $38(14 \%)$ \\
\hline -Yes & 41 & 12.20 & $36(87.8 \%)$ & $5(12.2 \%)$ \\
\hline Unknown & 8 & & & \\
\hline \multicolumn{5}{|c|}{ Bone densitometry } \\
\hline yes & 130 & 47.06 & $122(88.1 \%)$ & $8(11.9 \%)$ \\
\hline no & 180 & 52.94 & $152(85.9 \%)$ & $28(14.1 \%)$ \\
\hline Unknown & 11 & & & \\
\hline \multicolumn{5}{|l|}{$\begin{array}{l}\text { Counselling: } \\
\text { depression }\end{array}$} \\
\hline yes & 52 & 16.27 & $45(84.9 \%)$ & $7(1501 \%)$ \\
\hline no & 262 & 81.02 & $230(87.8 \%)$ & $32(12.2 \%)$ \\
\hline Unknown & 7 & & & \\
\hline \multicolumn{5}{|l|}{ Nutrition } \\
\hline yes & 73 & 22.46 & $64(87.7 \%)$ & $9(12.3 \%)$ \\
\hline no & 242 & 74.25 & $208(86 \%)$ & $34(14 \%)$ \\
\hline $\begin{array}{l}\text { Unknown } \\
\text { exercise }\end{array}$ & 6 & & & \\
\hline yes & 25 & 7.49 & $22(88 \%)$ & $3(12 \%)$ \\
\hline no & 287 & 88.92 & $250(86.5 \%)$ & $39(13.5 \%)$ \\
\hline Unknown & 7 & & & \\
\hline
\end{tabular}




\section{Discussion}

Cardiovascular diseases (CVD) are major causes of morbidity and mortality in the elderly. In our elderly women the prevalence of CVD risk factors like hypertension, dyslipidemia, diabetes mellitus and obesity are high. This may be explained by the high prevalence of ischemic heart disease (IHD) $24.71 \%$.On other hand only $6.5 \%$ of patients had cerebral vascular accident (CVA).86.18\% of elderly women had hypertension and all43 patients above 80 are hypertensive. In a long-term care facility hypertension was found in $60 \%$ of older women, mean age 81 years ${ }^{(7)}$. Multiple trials have been shown that not only is it safe to treat hypertension in the elderly, but it will decrease stroke, heart failure, myocardial infarction and all-cause mortality ${ }^{(8)} .69 .32 \%$ of elderly women have diabetes mellitus. In the DECODE study (Diabetes Epidemiology: Collaborative analysis of Diagnostic criteria in Europe) the prevalence of diabetes was $10-20 \%$ in individuals aged 60 79 years ${ }^{(9)}$.Dyslipidemia found in $60.36 \%$ of elderly women. Lipid management has received less attention in elderly women because their age at onset of IHD events tends to be later than in men. Physicians need to consider aggressive lipid-lowering therapy in older especially if they have IHD (10)

Obesity is defined by BMI $\geq 30 \mathrm{~kg} / \mathrm{m}^{2}$. In our study the mean BMI is 33.9 for all the patients, for age $65-79$ is 34.2 and for age 80 and above is 31.1 Obesity is more common in elderly women than in men ${ }^{(11)}$.In 2000 , the prevalence of obesity in elderly in USA increased to $22.9 \%$ in60-69 y of age and $15.5 \%$ in $>70$ y old ${ }^{(12) . .}$ In 2013 Saudi survey included all different age groups (young and elderly) found obesity in female is $33.5 \%$. Almost half of women are physically inactive, while $29 \%$ had low levels of physical activity. Data taken from the Coronary Artery Disease in Saudis Study showed inactivity prevalence is $96.1 \%$. There are significantly more inactive females $(98.1 \%)$ than males $(93.9 \%)$ and $99.2 \%$. female age 60 to 70 are inactive. These findings reveal the sedentary nature of Saudi population. The high prevalence of inactivity among Saudis represents a major public health concern ${ }^{(13,14)}$.Sedentary lifestyles will lead to obesity and increase the risk of diabetes, hypertension and dyslipidemia.

Self-reported functional capacity, particularly mobility, is diminished in overweight and obese compared with lean elderly adults ${ }^{(15)}$.A 3-unit increase in BMI is associated with a 1-point decrease in physical performance test score. A BMI $\geq 30$ in elderly are associated with physical dysfunction and are predictive of a decline in functional status and future disability ${ }^{(16)}$.Data from several recent studies found that obesity is an important cause of frailty in older persons ${ }^{(17)}$.

Osteoarthritis is the leading cause of physical disability in elderly. $47.35 \%$ of elderly women have osteoarthritis. High BMI is associated with an increased risk of knee osteoarthritis ${ }^{(18)}$.Physical disability and comorbidities in elderly can affect the functional status and quality of life. Functional status is directly influenced by health conditions. Measurement of functional status can monitor response to treatment and its prognostic information for long-term care planning. Frailty occurs when impairment in function and reduction in physiologic reserves are severe enough to cause disability. Among elderly living in the community $20 \%$ of those $>65$ y of age and $46 \%$ of those $>85$ y of age are considered to be frail ${ }^{(19)}$.Functional status documentation in $43.32 \%$ of patients charts. $36.30 \%$ of elderly women are full independent, $26.71 \%$ are requiring assistance of another person, $28.77 \%$ are using wheelchair and $8.22 \%$ are Bed bound. Osteoarthritis has impact on functional status among the elderly. Osteoarthritis reported in 24 of patients are full independent, 25 of patients are requiring assistance, 7 patients using wheelchair and 21 patients are Bed bound.

The prevalence of renal disease is $16.91 \%$ in elderly women and the commonest is chronic kidney disease (CKD) $78.57 \%$.It could be related to high prevalence of hypertension, diabetes and age effect. In a UK-based crosssectional study, the prevalence of CKD age 75 years was $56.1 \%{ }^{(20)}$. In another study the prevalence of CKD is $50 \%$ in 70 years old and $38 \%$ of this age group has stage 3 or stage 4 CKD ${ }^{(21)}$.CKD is associated with significant decline in both physical and cognitive function ${ }^{(22)}$. The prevalence of respiratory and hepatic diseases in our patient is low.

The prevalence of osteoporosis in elderly women is $26.84 \%$. The prevalence of osteoporosis in Saudi women was $44.5 \%$ using the manufacturer's reference values compared to only $28.2 \%$ when the Saudi reference values were used $^{(23)}$.In spite of high prevalence of osteoporosis in elderly women the bone density testing requested in $47.06 \%$ of the patients. In other study bone density testing was done in $23 \%$ of women ${ }^{(24)}$.

The effect of vitamin D on bone health has been well established. Prevalence of vitamin D deficiency increased between Saudi males and females ${ }^{(25)}$.The prevalence of vitamin D deficiency was high in both premenopausal $80 \%$ and postmenopausal $68 \%$ during the summer and during the winter $85 \%$ and $76 \%$, respectively ${ }^{(26)}$.Vitamin D level checked in $48.67 \%$ of the patients known to have vitamin D deficiency and $51.33 \%$ of patients as screening test. Measurement of vitamin D levels is expensive, and universal screening is not supported. Elderly is high risk group for vitamin $\mathrm{D}$ deficiency and it is appropriate to measure the level routinely. Hypothyroidism is more common in elderly, especially women and the incidence of hypothyroidism steadily increases with age. TSH level checked in $34.41 \%$ of the patients known to have hypothyroidism and $56.76 \%$ as screening test for hypothyroidism. The U.S. Preventive Services Task Force (USPSTF) found insufficient evidence to recommend for or against routine screening for thyroid disease.

Polypharmacy is common among the elderly due to the need to treat the several disease that develop as a patient ages. There have been numerous studies that have documented 
polypharmacy in elderly ${ }^{(27)}$. We found $83.98 \%$ of our patients are using more than 5 medications. It has been estimated that $20 \%$ of Medicare beneficiaries have five or more chronic conditions and $50 \%$ receive five or more medications ${ }^{(28)}$. Elderly are at greater risk for adverse drug events due to metabolic changes and decreased drug clearance associated with aging. Polypharmacy increases the potential for drugdrug interactions ${ }^{(29,30)}$.

We found that immunization is deficient among our patients. Only $29.76 \%$ of patients receive influenza vaccine and $12.20 \%$ of patients receive pneumococcal vaccine. Studies have found that only $60-65 \%$ of older US adults receive pneumococcal and/or influenza vaccinations ${ }^{(31)}$.

Herpes zoster vaccine is approved for immunocompetent adults over 60 years. In a large retrospective cohort study, vaccination reduced the risk of herpes zoster by $55 \%$, with risk reduction seen in both healthy older adults and those with chronic disease such as diabetes or coronary artery disease ${ }^{(32)}$.

Mammography for Breast cancer screening requested for $12.80 \%$ of patients. Studies have shown that around $50 \%$ of patients with breast cancer are those older than 65 years of age and $35 \%$ are older than 70 years ${ }^{(33)}$. There are very few retrospective and prospective studies looking specifically at cancer screening in the elderly. The USPSTF recommends extending mammography screening to age 74. Guidelines recommend individualizing screening mammography decisions for women aged 75 years and older. For women with less than a 10-year life expectancy, recommendations are to stop screening mammography ${ }^{(34)}$.

Pap smear for cervical cancer screening is requested for $8.31 \%$ of the patients. The incidence of cervical cancer in patients older than 65 years of age is 1.2 times the incidence of cervical cancer in the age group $45-64$ years ${ }^{(35)}$.The USPSTF recommends stopping screening at age 65. American cancer society (ACS) recommends stopping screening at age 70 for women who have had adequate recent screening with normal Pap smears and are not at high risk.

For colorectal cancer screening the colonoscopy is done in $9.64 \%$, Flexible sigmoidoscopy in $8.41 \%$, and Faecal occult in $15.32 \%$. It is reasonable to stop screening at age 75 years. In fact, age is the greatest single risk factor for colorectal cancer. Age-specific incidences in patients older than 80 years approximate 465/100 000 in men and 365/100 000 in women (36)

We reviewed the counselling for depression, exercise and nutrient. Counselling for depression provided to only $16.27 \%$ of elderly women. Identification of older women with depression is often neglected by primary care physicians ${ }^{(37)}$.The USPSTF recommend screening all adults for depression, although the optimal screening interval is unknown. Depression by far remains the most frequent psychiatric disorder mimicking or associated with dementia in the elderly ${ }^{(38,39)}$. The prevalence of depression and associated factors in Saudi elderly are studied in national survey Depressive symptoms are reported in $39 \%$ of the subjects, and $8.4 \%$ are in the severe depressive symptoms score group ${ }^{(40)}$. Depression has a significant impact on quality of life, outcomes of medical disease, morbidity and mortality. Depression in elderly can present atypically with cognitive, functional or sleep problems as well as complaints of fatigue or low energy.

Counselling for nutrition provided to $22.46 \%$ of the patients. Despite the clear relationship between undernutrition and increased morbidity and mortality, there are no well-validated general laboratory screens for this condition. A combination of serial weight measurements obtained in the office and inquiry about changing appetite are likely the most useful methods of assessing nutritional status in the elderly. Data from all studies found that older men and women who lost weight, or who experienced weight variability, had an increased relative mortality risk compared with those who were weight stable ${ }^{(41)}$.Exercise counselling is provided to $22.46 \%$ and other studies have found that $28 \%$ of older women receive exercise counselling ${ }^{(42)}$. Aging causes a progressive decrease in physical function because of a continued decline in muscle mass and strength and an increase in joint dysfunction and arthritis. These impairments affect activities of daily living and quality of life. The benefits of regular exercise in the elderly include: Reduced risk factors of CVD, osteoporosis, obesity and depression ${ }^{(43)}$.A12-year study of death rates among more than 9,000 women aged 65 or over has found that, women who walked, danced, did the garden, swam or went to aerobics, had the lower chances of dying by $50 \%$, as compare to women have sedentary life ${ }^{(44)}$.

\section{Conclusion}

(1) Immunization, screening for osteoporosis and cancer in addition to counselling for depression, nutrition and exercise were deficient. It is important to increase the awareness of physicians about preventive health care for elderly women.

(2) High prevalence of chronic diseases in elderly will have a great demand on health services. There is an urgent need to prevent and control chronic diseases. The promotion of healthy lifestyles should be a major component of public health work. It required a comprehensive cultural and environment changes.

(3) Physical disability and comorbidities in elderly women can affect the functional status and quality of life. Measurement of functional status is important because it is directly influenced by health conditions.

(4) Elderly is high risk group for vitamin D deficiency and it is appropriate to measure the level routinely.

The limitations of our study are insufficient documentation; counseling might be done but not documented. The size of sample is small and being done in one center which may not adequately represent the whole country.

\section{Acknowledgments}

The authors are grateful to Mr. Abdelmoneim Eldali from BESC, Research Centre at KFSH\&RC for his effort in the 
statistical analysis of our study.

\section{References}

[1] Schonberg MA.Preventive health care among older women: missed opportunities and poor targeting. Am J Med. 2008 Nov;121(11):974-81.

[2] Pham HH,Delivery of preventive services to older adults by primary care physicians. JAMA. 2005 Jul 27;294(4):473-81.

[3] Schonberg MA, Preventive health care among older women in an academic primary care practice. Women's Health Issues. 2008 Jul-Aug;18(4):249-56.

[4] JAMAL S. JARALLAH. Factors associated with health perception of Saudi elderly. Journal of Cross-Cultural Gerontology 14: 323-334, 1999

[5] Walter LC, Lindquist K, Covinsky KE. Relationship between health status and use of screening mammography and Papanicolaou smears among women older than 70 years of age. Ann Intern Med. 2004 May 4;140(9):681-8.

[6] Goldberg TH, Chavin SI. Preventive medicine and screening in older adults. J Am Geriatr Soc. 1997 Mar;45(3):344-54.

[7] Aronow WS, Ahn C. Prevalence and incidence of cardiovascular disease in 1160 older men and 2464 older women in a long-term health care facility. J Gerontol Med Sci 2002;57A:M45-6.

[8] Nikolaos Lionakis. Hypertension in the elderly. World J Cardiol. 2012 May 26; 4(5): 135-147.

[9] DECODE study group. Age and sex specific prevalence of diabetes and impaired glucose regulation in 13 European cohorts. Diabetes Care, 26 (2003), pp. 61-69

[10] Madhan Shanmugasundaram, Dyslipidemia in the Elderly: Should it Be Treated? Clin. Cardiol. 33, 1, 4-9 (2010)

[11] Flegal KM, Carroll MD. Prevalence and trends in obesity among US adults, 1999-2000. JAMA 2002; 288: 1723-7.

[12] Okdad AH, Bowman BA.The continuing epidemics of obesity and diabetes in the United States. JAMA2001; 286: 1195-200.

[13] Memish ZA, El Bcheraoui C. Obesity and associated factors--Kingdom of Saudi Arabia, 2013. Prev Chronic Dis. 2014 Oct 9;11:E174

[14] Al-Nozha MM, Prevalence of physical activity and inactivity among Saudis aged $30-70$ years. A populationbased cross-sectional study. Saudi Med J. 2007 Apr;28(4):559-68

[15] Jenkins KR. Obesity's effects on the onset of functional impairment among older adults. Gerontologist2004; 44: 206-16.

[16] Jensen GL, Friedmann JM. Obesity is associated with functional decline in community-dwelling rural older persons. J Am GeriatrSoc 2002; 50: 918-23.

[17] Blaum CS, Xue QL. The association between obesity and the frailty syndrome in older women: The Women's Health and Aging Studies. J Am GeriatrSoc 2005; 53: 927-34.
[18] Hart DJ, Spector TD. The relationship of obesity, fat distribution and osteoarthritis in women in the general population: the Chingford Study. J Rheumatol 1993; 20: $331-5$.

[19] Ory MG, Schechtman KB et al. Frailty and injuries in later life: the FICSIT trials. J Am GeriatrSoc 1993; 41: 283-96.

[20] Roderick PJ, Atkins RJ et al. Detecting chronic kidney disease in older people; what are the implications? Age Ageing 37,179-186 (2008).

[21] Coresh J, Selvin E, Stevens L et al. Prevalence of chronic kidney disease in the United States. JAMA 298,2038-2047 (2007).

[22] Ahmed H Abdelhafiz; Shameela Ahmed; Is Chronic Kidney Disease in Older People a New Geriatric Giant?Aging Health. 2011;7(5):749-762.

[23] Ardawi MS, Maimany AA, Bahksh TM. Bone mineral density of the spine and femur in healthy Saudi Arabs. Osteoporos Int. 2005;16:43-55

[24] Neuner JM, Binkley N. Bone density testing in older women and its association with patient age. Journal of the American Geriatrics Society. 2006;54(3):485-489

[25] Elsammak MY, Vitamin d deficiency in Saudi Arabs.HormMetab Res. 2010 May;42(5):364-8.

[26] Kanan RM, Al Saleh YM,.Year-round vitamin D deficiency among Saudi female out-patients.Public Health Nutr. 2012 Jun 13:1-5

[27] Robert L. Maher, Jr. Consequences of Polypharmacy in Elderly. Expert Opin Drug Saf. 2014 Jan; 13(1): 10

[28] Tinetti ME, Bogardus ST Jr. Potential pitfalls of diseasespecific guidelines for patients with multiple conditions. $\mathrm{N}$ Engl J Med 2004; 351:2870

[29] Field TS, Gurwitz JH et al. Risk factors for adverse drug events among nursing home residents. Arch Intern Med $2001 ; 161: 1629$.

[30] Lai SW, Liao KF et al. Polypharmacy correlates with increased risk for hip fracture in the elderly: a populationbased study. Medicine (Baltimore) 2010; 89:295.

[31] Thompson WW, Shay DK et al. Mortality associated with influenza and respiratory syncytial virus in the United States. Journal of the American Medical Association. $2003 ; 289(2): 179-186$.

[32] Tseng HF, Smith N, Harpaz R, et al. Herpes zoster vaccine in older adults and the risk of subsequent herpes zoster disease. JAMA 2011; 305:160.

[33] Hua Wang, Breast Cancer Treatment Practices in Elderly Women in a Community Hospital. International Journal of Breast Cancer, Volume 2011 (2011).

[34] Walter LC, Schonberg MA.Screening mammography in older women: a review. JAMA. 2014 Apr 2;311(13):1336-47.

[35] McGowan L. The management of elderly patients with gynaecologic cancer. CurrOpinObstet Gynecol. 1995;7:53-56.

[36] Andreas Kirchgatterer, Colorectal cancer in geriatric patients: Endoscopic diagnosis and surgical treatment. World $\mathrm{J}$ Gastroenterol January 21, 2005 Volume 11 Number 3 
[37] Simon GE, VonKorff M. Recognition, management, and outcomes of depression in primary care. Archives of Family Medicine. 1995;4(2):99-105.

[38] Whooley, Case-finding instruments for depression. Two questions are as good as many. J Gen Intern Med 1997; $12: 439$.

[39] Pignone, et al. Screening for depression in adults: a summary of the evidence for the U.S. Preventive Services Task Force. Ann Intern Med 2002; 136:765

[40] Al-Shammari SA, Al-Subaie A. Prevalence and correlates of depression among Saudi elderly.Int J Geriatr Psychiatry. 1999 Sep;14(9):739-47.

[41] Dennis T Villareal, Caroline M Apovian. Obesity in older adults: technical review and position statement of the American Society for Nutrition and NAASO, The Obesity Society. American Journal of Clinical Nutrition, Vol. 82, No. 5, 923-934, November 2005

[42] Schonberg MA, Marcantonio ER, Wee CC. Receipt of exercise counseling by older women. Journal of the American Geriatrics Society. 2006;54(4):619-626.

[43] ThorleifEtgen; Dirk Sander. Physical Activity and Incident Cognitive Impairment in Elderly Persons: The INVADE Study. Arch Intern Med, 2010; 170 (2): 186-193

[44] Gregg EW et al.Relationship of Changes in Physical Activity and Mortality Among Older Women,Journal of the American Medical Association. 2003 vol 289 pp 2379-2386 